\title{
Acetylcholinesterase inhibitors in Alzheimer's disease
}

\section{B. M. McGleenon, K. B. Dynan \& A. P. Passmore}

Department of Geriatric Medicine, The Queen's University of Belfast, Belfast

\section{Introduction}

Alzheimer's Disease (AD) is the most common single cause of dementia in our ageing society. Traditionally thought of as an untreatable degenerative condition, recent advances in drug therapy have challenged this view.

The disease is characterised by an insidious decline in cognitive and non-cognitive function. Classically, short and long-term memory is impaired while language skills, concentration and attention are often affected. This results in impaired ability to learn and retain new skills as well as the loss of existing ones. Non-cognitive function is the global term used to describe problems such as depression, agitation, personality changes, delusions and hallucinations. These factors have a significant impact on patient behaviour and a very real impact on the quality of life for both patients and caregivers. Diagnosis of $\mathrm{AD}$ is clinically based, and using the NINCDS-ADRDA criteria (Table 1) [1], a diagnosis of probable or possible $\mathrm{AD}$ can be made. Definitive diagnosis relies on pathological confirmation, which in the majority of cases is rarely completed. With the development of AD specific treatments, definition of AD from other types of dementia is very important.

\section{Pathogenesis}

The pathogenesis of $\mathrm{AD}$ has not yet been elucidated. It is widely accepted that a combination of genetic susceptibility factors and environmental triggers are responsible for late onset sporadic $\mathrm{AD}$, the most common form of the disease. An understanding of the disease mechanism remains elusive, and is the key to developing a disease modifying agent. Currently, it is proposed that beta amyloid protein, abnormal tau protein or possibly both play key factors in the development of disease. It has been widely postulated that oxidative damage and a slow inflammatory process are two possible mechanisms involved. As yet, no product with proven disease modifying properties is available, and current treatments offer symptomatic benefit only.

The development of acetylcholinesterase (AChe) inhibitor drugs has followed the finding that cholinergic

Correspondence: Dr B. M. McGleenon, Department of Geriatric Medicine, Whitla Medical Building, 97 Lisburn Road, Belfast, BT9 7BL, Tel: (0I232) 272153, Fax: (01232) 325839.

Received 10 December 1998, accepted I June 1999. pathways in the cerebral cortex and basal forebrain are compromised in $\mathrm{AD}$ [2] and the resultant cholinergic deficit contributes to the cognitive impairment of these patients [3]. Although many believe this "cholinergic hypothesis' to be important, others feel it represents a less significant component of the disease process [4]. Many other neurotransmitters are affected in $\mathrm{AD}$, and the relative importance of each in relation to clinical findings has not been fully elucidated.

Initial work focused on the use of acetylcholine precursors, using a similar rationale to dopamine therapy in Parkinson's disease. A series of small trials using precursors such as choline and phosphatidylcholine showed no reliable improvement in cognitive function, with only 10 out of 43 trials reporting any positive effect [5]. There has been renewed interest in muscarinic agonists drugs, which when first introduced, had major problems with adverse cholinergic effects. Better understanding of the molecular pathology of muscarinic receptors and their subtypes has led to the development of more specific agonists. Drugs such as xanomeline, milameline, and civimeline have reached clinical trials, and the improvements seen in cognitive function are reviewed by Avery et al. [6]. There are also claims that these drugs have disease modifying properties, with effects on APP processing and tau phosphorylation. Muscarinic agonists remain in trial, but have yet to fulfil their potential in $\mathrm{AD}$ treatment. The only group of drugs currently licensed for $\mathrm{AD}$ treatment is the AChe inhibitors, which act through inhibition of the enzyme acetylcholinesterase (AChe), responsible for the breakdown of ACh in the neural synapse. A meta-analysis of the early AChe inhibitor treatments was encouraging [7] and these proceeded to larger placebo controlled doubleblind trials.

\section{AD assessments}

The advent of treatment for dementia has brought with it a confusing array of 'dementia' assessments, many designed specifically for the therapeutic trials. The majority of these are unfamiliar to physicians, as they have limited value in clinical settings. However, a cursory understanding of the many scores and abbreviations is essential for reviewing the published data (Table 2). The primary outcome measures in these trials most commonly include the ADAS Cog (Alzheimer's Disease Assessment 
Table 1 NINCDS-ADRDA Criteria for clinical diagnosis of Alzheimer's disease.

I The criteria for the clinical diagnosis of probable Alzheimer's disease include:

Dementia established by clinical examination and documented by the Mini-Mental Test, Blessed Dementia Scale, or some similar examination, and confirmed by neuropsychological tests.

Deficits in two or more areas of cognition

Progressive worsening of memory and other cognitive functions

No disturbances of consciousness

Onset between aged 40 and 90, most often after age 65

Absence of systemic disorders or other brain diseases that in and of themselves could account for the progressive deficits in memory and cognition

II The diagnosis of probable Alzheimer's disease is supported by:

Progressive deterioration of specific cognitive functions such as language (aphasia), motor skills (apraxia), and perception (agnosia)

Impaired activities of daily living, and altered patterns of behaviour

Family history of similar disorders, particularly if confirmed neuropathologically and

Laboratory results of:

normal lumbar puncture as evaluated by standard techniques

normal pattern or non-specific changes in EEG, such as increased slow-wave activity

evidence of cerebral atrophy on CT with progression documented by serial observation

III Other clinical features consistent with the diagnosis of probable Alzheimer's disease, after exclusion of causes of dementia other than

Alzheimer's disease, include:

Plateaus in the course of progression of the illness

Other neurologic abnormalities in some patients, especially with more advanced disease and including motor signs such as increased

muscle tone, myoclonus, or gait disorder

Seizures in advanced disease

CT normal for age

IV Features that make the diagnosis of probable Alzheimer's disease uncertain or unlikely include:

Sudden, apoplectic onset

Focal neurologic findings such as hemiparesis, sensory loss, visual field deficits, and incoordination early in the course of the illness

Seizures of gait disturbance at the onset or very early in the course of the illness

V Clinical diagnosis of possible Alzheimer's disease:

May be made on the basis of the dementia syndrome, in the absence of other neurologic, psychiatric, or systemic disorders sufficient to cause dementia, and in the presence of variations in the onset, in the presentation, or in the clinical course

May be made in the presence of a second systemic or brain disorder sufficient to produce dementia, which is not considered to be the cause of the dementia

Should be used in research studies when a singe, gradually progressive severe cognitive deficit is identified in the absence of other identifiable cause

VI Criteria for diagnosis of definite Alzheimer's disease are:

The clinical criteria for probably Alzheimer's disease

Histopathologic evidence obtained from a biopsy or autopsy

VIII Classification of Alzheimer's disease for research purposes should specify features that may differentiate subtypes of the disorder, such as: Familial occurrence

Onset before age of 65

Presence of trisomy-21

Scale Cognitive Subscale), some form of global assessment such as the CIBIC (Clinicians Interview-Based Impression of Change) scale or the CGIC (Clinical Global Impression of Change) and a staging scale for dementia, the CDR (Clinical Dementia Rating scale).

The ADAS Cog has been the mainstay of cognitive testing in recent dementia trials [8]. It assesses the major cognitive functions of memory, language, attention, orientation, praxis and reasoning. It is scored from 0 to 70 , with a higher score indicating increasing severity. The test is most sensitive in the middle phase of disease, with moderately severe AD patients gaining approximately $7-11$ points per year $[9,10]$. The CIBIC Score, usually performed by a separate rater, is information from patient and carer (CIBIC-Plus) obtained during interview and focuses on general well being, cognition, behaviour and activities of daily living (ADL). It provides a global assessment of deterioration in the absence of any knowledge of the psychometric test performance. It was derived from the CGIC, a similar rating to the CIBIC score employed in earlier donepezil and tacrine trials [11]. The CDR [12] is a consensual report from all assessors, on six main functional domains; memory, orientation, judgement, community affairs, home and hobbies and personal care. The scale defines mild, moderate and severe dementia. 
Table 2 Scores and abbreviations used in assessing Alzheimer's disease.

\begin{tabular}{|c|c|c|}
\hline Score & Rating & Type \\
\hline $\begin{array}{l}\text { AD assessment score- } \\
\text { cognitive subscale. } \\
\text { ADAS Cog }\end{array}$ & $\begin{array}{l}0-70 \\
\text { Lower score indicates } \\
\text { improvement }\end{array}$ & Cognitive assessment using questionnaire with patient (single assessor) \\
\hline $\begin{array}{l}\text { Clinician's impression of } \\
\text { change CIBIC (plus) }\end{array}$ & $\begin{array}{l}\text { 1-7 lower score indicates } \\
\text { improvement }\end{array}$ & $\begin{array}{l}\text { Global Assessment independent of psychometric test results. Uses interview } \\
\text { technique with both patient and carer (single assessor) }\end{array}$ \\
\hline $\begin{array}{l}\text { Clinical global impression } \\
\text { of change CGIC }\end{array}$ & $\begin{array}{l}\text { 1-7 lower score indicates } \\
\text { improvement }\end{array}$ & $\begin{array}{l}\text { Global Assessment independent of psychometric test results. Uses interview } \\
\text { technique with patient and caregiver (single assessor) }\end{array}$ \\
\hline $\begin{array}{l}\text { Clinical dementia rating } \\
\text { (sum of the boxes) } \\
\text { CDR-SB }\end{array}$ & $\begin{array}{l}\text { Mild dementia } \\
\text { Moderate dementia } \\
\text { Severe dementia }\end{array}$ & $\begin{array}{l}\text { Global assessment of disease severity in } 6 \text { areas of function } \\
\text { (consensual report from all assessors }\end{array}$ \\
\hline $\begin{array}{l}\text { Global deterioration scale } \\
\text { GDS }\end{array}$ & $\begin{array}{l}1-7 \text { lower score indicates less } \\
\text { cognitive decline }\end{array}$ & $\begin{array}{l}\text { Global assessment of disease severity (cognition, self-care and ADLS) from } \\
\text { both patient and carer (single assessor) }\end{array}$ \\
\hline $\begin{array}{l}\text { Folstein mini-mental state } \\
\text { examination. MMSE }\end{array}$ & $\begin{array}{l}0-30 \text { Lower score indicates } \\
\text { deterioation }\end{array}$ & $\begin{array}{l}\text { Cognitive assessment using questionnaire with patient } \\
\text { (single assessor) }\end{array}$ \\
\hline $\begin{array}{l}\text { Instrumental activities of } \\
\text { daily living. IADL }\end{array}$ & $\begin{array}{l}4-32 \text { Lower score indicates } \\
\text { improvement }\end{array}$ & $\begin{array}{l}\text { Functional assessment using questionnaire with carer } \\
\text { (single assessor) }\end{array}$ \\
\hline $\begin{array}{l}\text { Physical self maintenance } \\
\text { scale. PSMS }\end{array}$ & $\begin{array}{l}\text { 6-30 Lower score indicates } \\
\text { improvement }\end{array}$ & $\begin{array}{l}\text { Functional score using questionnaire with carer } \\
\text { (single assessor) }\end{array}$ \\
\hline $\begin{array}{l}\text { Progressive deterioration } \\
\text { scale. PDS }\end{array}$ & $\begin{array}{l}0-100 \text { Lower score indicates } \\
\text { deterioration }\end{array}$ & $\begin{array}{l}\text { Quality of life assessment using questionnaire with patient } \\
\text { (single assessor) }\end{array}$ \\
\hline $\begin{array}{l}\text { Quality of life } \\
\text { QoL (carer) QoL } \\
\text { (patient) }\end{array}$ & $\begin{array}{l}\text { Patient rated score of } 7 \text { areas } \\
\text { of well-being }\end{array}$ & $\begin{array}{l}\text { Quality of life assessment using questionnaire with patient and carer } \\
\text { (single assessor) }\end{array}$ \\
\hline $\begin{array}{l}\mathrm{AD} \text { assessment score if } \\
\text { non cognitive function } \\
\text { ADAS nonCog }\end{array}$ & $\begin{array}{l}0-45 \text { Lower score indicates } \\
\text { improvement }\end{array}$ & $\begin{array}{l}\text { Non cognitive assessment using questionnaire with patient and carer } \\
\text { (single assessor) }\end{array}$ \\
\hline $\begin{array}{l}\text { Neuropsychiatric } \\
\text { inventory NPI }\end{array}$ & $\begin{array}{l}\text { Frequency and severity of } 10 \\
\text { areas of behaviour }\end{array}$ & Non cognitive assessment using questionnaire with carer \\
\hline $\begin{array}{l}\text { Behavioural pathology in } \\
\text { Alzheimer's disease } \\
\text { BEHAVE AD }\end{array}$ & $\begin{array}{l}0-75 \text { lower score indicates } \\
\text { improvement }\end{array}$ & $\begin{array}{l}\text { Behavioural assessment of } 7 \text { distinct areas of patient behaviour, using } \\
\text { questionnaire with carer (single assessor) }\end{array}$ \\
\hline
\end{tabular}

Secondary outcome measures used in trials are more variable, and attempt to assess areas such as daily function and quality of life. Mini-mental state examination (MMSE) [13] and Activities of Daily Living (ADL) [14] are cited along with less well known assessments such as the Geriatric Evaluation by Relatives Rating Instrument (GERRI) [15], the Progressive Deterioration Scale (PDS) [16] and the Global Deterioration Scale (GDS) [17] which is used as a measure of severity rather than deterioration. Non cognitive function is more difficult to quantify, and assessments usually encompass some form of behavioural rating scale such as the ADAS noncognitive Score, neuropsychiatric inventory (NPI) [18] or the Behavioural Pathology in Alzheimer's Disease (BEHAVE-AD) [19]. A lack of consensus regarding appropriate non-cognitive and functional assessments is reflected in the variety of scales used.

An obvious need for standardisation became apparent, and in 1989, the American Food and Drug Administration (FDA) published guidelines outlining what they felt constituted a clinical response in dementia treatment [20].
This has since been employed by the European Medicine Evaluation Agency (EMEA) [21]. They designated a change of 4 points or more on an ADAS Cog score within a clinical trial setting to represent a significant clinical effect. This was based on the calculation that the 'average' AD patient will show a decline in their ADAS Cog score of 7 to 11 points per year in the middle stages of disease [9, 10]. Thus, an improvement of 4 points in the ADAS Cog is felt to represent a gain of 6 months in terms of delaying decline. Due to the heterogenous nature of $\mathrm{AD}$, a 6 month delay can represent a huge variation in clinical terms. In practice this can mean improved insight, better memory with less repeated questioning, improved fluency in language, improved recognition of people, and revived interest in hobbies or everyday events. A problem with using the ADAS Cog as a gold standard is that factors such as mood, behaviour and functional ability are not considered. Certain AChe inhibitor trials have highlighted positive effects (in addition to the 4-point ADAS Cog improvement) on neuropsychiatric symptoms, in particular hallucination 
[22], and ADLs [23]. In reference to this problem, the FDA and EMEA have highlighted the importance of global assessments in conjunction with cognitive scores, and these are included as measures of primary efficacy in clinical trials.

\section{AChe inhibitors-pharmacology}

As a group, these drugs show a dose-dependent improvement in symptoms of $\mathrm{AD}$, with varying amounts of systemic cholinergic effects. The early research into AChe inhibitors included tetrahydroaminoacridine (tacrine), physostigmine and velnacrine. Of these, only tacrine proceeded to large-scale clinical trials and commercial launch in the USA and parts of Europe. This has been followed by the more recent products, donepezil, rivastigmine and metrifonate (Table 3 ).

Tacrine, an aminoacridine, has several actions such as monoamine oxidase inhibition, potassium channel blockade and interaction with subtypes of muscarinic and nicotinic receptors. However the most prominent action is as a centrally active reversible cholinesterase inhibitor. Tacrine is rapidly absorbed and cleared by the liver during a first pass metabolism [24, 25]. Due to hepatic hydroxylation, tacrine itself has a very low bioavailability when taken orally, at $2 \%$ to $3 \%$ that of an intravenous dose. The short, markedly variable elimination half-life of tacrine increases from 1.4 to $3.6 \mathrm{~h}$ with higher doses and multiple dosing. The relationship between dosage and bioavailability is not proportional e.g. doubling the dose may triple or quadruple bioavailability. Tacrine is rapidly taken up into the brain where its concentration is tenfold that in plasma $[25,26]$. In summary the characteristics of tacrine's pharmacokinetics are dose nonlinearity, extensive distribution, and rapid elimination through hepatic transformation, mainly into the hydroxy metabolite velnacrine.

Donepezil is a specifically designed piperidine derivative with reversible acetylcholinesterase inhibitor activity. It has a much higher specificity for acetylcholinesterase inhibition compared with tacrine [27] and its CNS selectivity is highlighted by the lack of activity in peripheral tissue such as cardiac tissue or gut smooth muscle [28]. The pharmacokinetics are linear and dose proportional, with peak plasma levels after approximately $4 \mathrm{~h}$. Plasma steady state appears to be reached between 14 and 21 days with a long half-life of over $70 \mathrm{~h}$ [29]. Excretion is slow and occurs via renal and the cytochrome P450 system although it is not impaired in patients with hepatic or renal impairment [30].

Rivastigmine is a brain selective carbamate AChe inhibitor. It is known as a 'pseudo-irreversible' inhibitor because it mimics $\mathrm{ACh}$ by binding with the enzyme AChe forming a carbamylated complex. This prevents further enzyme-catalysed hydrolysis of ACh for several hours after the drug has been eliminated from the plasma. Thus, despite a half-life of only $1 \mathrm{~h}$, rivastigmine has a duration of action of about $10 \mathrm{~h}[31,32]$. Like donepezil, rivastigmine has marked CNS selectivity [31, 33], with animal studies showing specific effect in the cortex and hippocampus [33]. Rivastigmine does not bind appreciably to plasma proteins, and is inactivated by cleavage during the enzyme inhibition. This avoids hepatic metabolism, and the drug is rapidly excreted through the kidneys.

Metrifonate has a 30-year history as a treatment for schistosomiasis. Only in the late 1980s was it considered as a potential treatment for $\mathrm{AD}$ on the basis of its anticholinesterase properties. It has a short half-life in plasma (2h), but has long activity in the CNS due to its irreversible activity. It is hydrolysed non-enzymatically to the active metabolite 2,2-dimethyl dichlorovinyl phosphate (DDVP). It is this compound that binds stably to the catalytic site for the enzyme, and provides sustained AChe inhibition in the CNS [34]. It is rapidly absorbed and distributed to the brain, although lacking in specificity for central inhibition. In plasma, it remains mostly unbound $(<15 \%)$ to proteins and avoids the cytochrome P450 system.

Previous clinical experience of the drug indicated only mild cholinergic side effects with high levels of AChe inhibition $(>80 \%)$ and short treatment periods [35]. The

Table 3 Characteristics of some AChe inhibitors.

\begin{tabular}{|c|c|c|c|c|}
\hline Drug & Type & $\begin{array}{l}\text { Half-life } \\
\text { (plasma) }\end{array}$ & Dose & Elimination \\
\hline Tacrine & Aminoacridine & $1.4-3.6 \mathrm{~h}$ & Four times daily & $\begin{array}{l}\text { Hepatic } \\
\text { hydroxylation }\end{array}$ \\
\hline Donepezil & Piperidine & $70 \mathrm{~h}$ & Once daily & $\begin{array}{l}\text { Dual excretion- } \\
\text { Cytochrome P450 } \\
\text { and renal }\end{array}$ \\
\hline Rivastigmine & Carbamate & $1 \mathrm{~h}$ & Twice daily & Renal \\
\hline Metrifonate & DDVP (active metabolite) & $\begin{array}{l}2 \mathrm{~h} \\
\text { (prolonged CNS activity) }\end{array}$ & Once daily & Renal \\
\hline
\end{tabular}


safety of metrifonate in long-term treatment is currently under review, with recent trials highlighting a possible link with muscle weakness.

\section{Efficacy}

\section{Tacrine}

The early trials of tacrine roused interest by reporting improvements in cognitive function but the small number of patients limited their usefulness. In the double-blind, placebo-controlled, crossover study of tacrine plus lecithin reported by Eagger et al., only 65 patients completed the treatment [36]. However, most of the findings were subsequently confirmed in the larger multi-centre trials that followed. In clinical trials involving around 2400 patients in the USA, Canada and France, tacrine showed a clinically observable response in $20-30 \%$ of patients. In one of the larger trials clinically significant improvements were seen in the ADAS Cog score $(P<0.002)$, CIBIC $(P<0.04)$ and GDS $(P<0.01)$ at a dose of $160 \mathrm{mg}$ [37]. These changes were not statistically significant for the lower doses of tacrine in this study although they were seen to a lesser degree in another study [38]. Forty percent of patients still taking the higher dose of tacrine $\left(160 \mathrm{mg} \mathrm{day}^{-1}\right)$ at completion showed the significant 4 points or more improvement in ADAS Cog. However this figure drops to $27 \%$ in the intent to treat analysis (ITT) due to the huge withdrawal rate (70\%) at this dosage [37]. Most patients withdrew because of elevations in serum alanine aminotransferase (ALT).

The results of a 2-year follow up study of AD patients in the open label phase of the above mentioned trial [37] showed that patients who tolerated tacrine at $>80 \mathrm{mg} \mathrm{day}^{-1}$ dose, had lower risk of nursing home placement (NHP) than those who either discontinued the drug or continued on lower doses [39]. High-dose treated patients were 2.8 times less likely to be institutionalised than low-dose treated patients but these results need to be interpreted with caution due to methodological limitations of the study. The major limitations are that the treatment assignment was not random nor was it blinded after 30 weeks so a causal relationship between higher dose tacrine treatment and more favourable outcomes cannot be categorically stated.

Recently published data on the long term effects of tacrine in the same group of non-institutionalised patients found only slightly different scores on the Physical Self Maintenance Scale (PSMS, a measure of basic ADLs) in patients on high dose tacrine indicating less decline. There were no significant group differences on the MMSE, the GDS or the Instrumental Activities of Daily Living Scale. The authors concluded that 'the conservative view' was that tacrine had no appreciable benefits at 2 years after therapy initiation [40].
A meta-analysis of 12 trials of tacrine encompassing 1984 patients with AD was recently published [41]. This meta-analysis, which only focused on the first 12 weeks of treatment, provided evidence that tacrine has an overall beneficial, but small, effect on cognitive function and the CGIC. They also found that effects observed on measures of behavioural disturbance were of questionable clinical significance, and functional autonomy was not significantly affected. The authors concluded that there remained three important issues that their study was not able to address and which have relevance to the other 'newer' cholinesterase inhibitors. First, the relationship between treatment effect and dose was difficult to assess because in most studies the dose for each patient was titrated to the patient's 'best' dose. Second, there is lack of controlled data on clinically important end points such as dependence and institutionalisation. Third, the lack of long-term studies also means it is not possible to assess whether the beneficial effects of continuous therapy reach a plateau, how long these endure, or when it is best to withdraw treatment. Furthermore they point out that none of the cholinesterase inhibitors has reliable controlled data on meaningful outcomes such as dependency and institutionalisation or other aspects of long-term efficacy and that such trials were urgently needed. It is apparent from this meta-analysis and the available long-term studies $[39,40]$ that construction of well designed long term trials face major logistical difficulties because of issues relating to placebo control, prolonged study duration and ethical considerations.

\section{Donepezil}

Launched last year, donepezil (Aricept) was the first AChe inhibitor available for prescription in the United Kingdom. It was received with mixed reactions, largely associated with questions of cost rather than efficacy. In 1996, a 14 week, double-blind US trial enrolled 161 patients testing doses of 1,3 , and $5 \mathrm{mg}$, against placebo. There was a significant difference in the ADAS Cog score with the $3 \mathrm{mg}(P<0.036)$ and $5 \mathrm{mg}(P<0.002)$ dose when compared with controls, and evidence for an overall dose response trend. This trend for improvement was also seen in the global assessment, with $11 \%$ treatment failures in the $5 \mathrm{mgs}$ group compared with $20 \%$ in the placebo group $(P=0.039)$ [42]. As a result of this study, higher doses were needed in subsequent trials. The most recently published donepezil trials have compared $5 \mathrm{mg}$ and $10 \mathrm{mg}$ with placebo showing a dose dependent improvement in cognitive and global function [43, 44]. On completion of the 24 week trial, ADAS Cog scores showed an average difference from placebo of 2.49 $(P<0.0001)$ and $2.88 \quad(P<0.0001)$ for 5 and $10 \mathrm{mg}$ respectively [43]. This trial also published data using the 
4-point ADAS Cog improvement, with 53.3\% of the observed cases (OC) on $10 \mathrm{mg}$ achieving those targets compared with $26.8 \%$ of those on placebo. When the ITT figures are used, $26 \%$ of this high dose group achieved the 4-point change. The CIBIC score was marginally significant at $5 \mathrm{mg}(P<0.047)$, and more convincingly improved at $10 \mathrm{mg}(P<0.0001)$ when compared to controls. Quality of life scores did not show consistent statistical significance, but the CDR score showed a significant mean drug placebo difference of 0.6 for both $5 \mathrm{mg}$ and $10 \mathrm{mg}$ at completion $(P<0.0008)$. Completion rates for the trial were good with $80 \%, 85 \%$ and $68 \%$ of the placebo, $5 \mathrm{mg}$ and $10 \mathrm{mg}$ groups respectively reaching the 24 weeks, reflecting an improved side effect profile.

There is now longer term data available with interim results (at 98 weeks) of an open label study using up to $10 \mathrm{mgs} /$ day of donepezil [45]. The improvements in ADAS Cog and CDR-SB seen initially were maintained at 38 and 26 weeks respectively. The lack of a placebo group means the subsequent clinical decline (a rise of 6.6 points/year in the ADAS Cog) in the study group is calculated to be less than that seen in a projected untreated group (rise of 11.6 points/year) when the baseline ADAS cog scores are taken into account. This slower deterioration is also seen in the CDR-SB, which showed an average decline of 1.8 points per year compared with a predicted decline of 2.4 points per year in untreated patients [12]. The safety profile at 98 weeks is similar to that seen in the shorter placebo controlled trials, with no additional adverse events, or clinically significant changes in monitored laboratory values.

\section{Rivastigmine}

Rivastigmine (Exelon), a carbamate derivative, is the latest in this group of drugs to be launched in the UK. The ADENA programme is the name given to the Rivastigmine phase III clinical trials. It is claimed to be the largest global study to date of a new treatment for AD. In the four studies that it encompasses, 3300 people with mild to moderately severe AD have been recruited. The ADENA-2 study [46] randomised patients with mild to moderately severe $\mathrm{AD}$ to treatment with placebo, low dose rivastigmine $\left(1-4 \mathrm{mg} \mathrm{day}^{-1}\right)$ or higher doses $\left(6-12 \mathrm{mg} \mathrm{day}^{-1}\right)$. Of the 699 patients enrolled into the trial $78 \%$ completed treatment although in the high dose rivastigmine group 35\% discontinued, primarily due to adverse events. The fact that a significant proportion of the subjects were in the older age range (average age 74.5 years, no upper age limit) with a high rate of co-morbidity seems to address the previous criticism of $\mathrm{AD}$ trials. Patients receiving the high dose rivastigmine $\left(6-12 \mathrm{mg} \mathrm{day}^{-1}\right)$ maintained their baseline level of performance on the ADAS-Cog in contrast to the placebo group who deteriorated with a treatment difference of 3.78 points $(P<0.001)$. In the $\mathrm{OC}$ analysis one quarter of the patients on the high dose rivastigmine showed the 4 point rise in the ADAS-Cog deemed by the FDA to be clinically meaningful. The paper did not specify what proportion of subjects on the low dose rivastigmine or placebo achieved this rise, nor did it state what proportion of the high dose group achieved this rise in the ITT analysis. Less deterioration was seen in the CIBIC Plus rating in both high and low dose groups $(P<0.01$ and $P<0.05$ respectively). These changes were greater and of more rapid onset in the high dose group. A quarter of the high dose group (OC analysis) showed a clinically meaningful improvement in the measurements of activities of daily living with a $10 \%$ improvement in the PDS score $(P=0.006)$. This benefit was not seen in the low dose group.

A parallel study of almost identical design carried out predominantly in Europe has recently been published [23]. A total of 725 patients were enrolled and randomly allocated to placebo, low dose rivastigmine $\left(1-4 \mathrm{mg} \mathrm{day}^{-1}\right)$ or higher dose rivastigmine $\left(6-12 \mathrm{mg} \mathrm{day}^{-1}\right)$. At the end of the study the mean dose of rivastigmine was $10.4 \mathrm{mg} \mathrm{day}^{-1}$ in the higher dose group and $3.7 \mathrm{mg} \mathrm{day}^{-1}$ in the lower dose group; these were slightly higher than the average doses in the earlier study of $9.7 \mathrm{mg} \mathrm{day}^{-1}$ and $3.5 \mathrm{mg}$ day $^{-1}$ respectively. The results reported were similar to those of the previous study. The 4 points or greater improvement in the ADAS-cog was seen in $24 \%$ of the higher dose group compared to $16 \%$ in the placebo group (ITT analysis); $29 \%$ vs 19\% OC analysis. Improvements in the CIBIC rating were also seen in both treatment groups at 26 weeks with $20 \%$ placebo group, 30\% lower dose group and $37 \%$ higher dose group showing marked, moderate, or minimal improvement in the ITT analysis. The assessment of activities of daily living using the PDS showed significantly less deterioration between the higher dose group and placebo in the analysis of the last observation carried forward $(P<0.05)$ but this finding was not significant in the ITT analysis $(P<0.1)$. Significantly more patients in the higher dose group improved by at least $10 \%$ than in the placebo group $(29 \%$ vs 19\%) ITT analysis. No beneficial effects on the PDS were noted in the lower dose group.

\section{Metrifonate}

Metrifonate is another AChe inhibitor which has reached phase 3 clinical trials. In 1990, a small open label study highlighted the potential benefit of metrifonate in AD [47]. This has been followed by two larger placebocontrolled trials, assessing dosage regimens and efficacy in 
over 400 patients [22, 48]. Results have been comparable with the major donepezil trial. Patients treated with a weight adjusted medium dose $\left(0.3 \mathrm{mg} \mathrm{kg}^{-1}\right)$ and high dose $\left(0.65 \mathrm{mg} \mathrm{kg}^{-1}\right)$ of metrifonate showed an average $1.3(P<0.053)$ and $2.94(P<0.0001)$ point difference respectively in the ADAS Cog score compared with placebo. CIBI plus score also reached a significant change from placebo in the medium and high dose groups with an average difference of $0.29(P<0.005)$ and 0.35 $(P<0.0007)$ respectively [48]. More interestingly, in a trial of high dose metrifonate, there was a significant change in the NPI, with a 2.75 point difference between the treated and placebo group $(P<0.0161)$. In particular, the incidence of hallucinations was significantly less in the treated group $(P<0.002)$ [22]. The NPI is a noncognitive assessment and an area where AChe inhibitors have traditionally shown poor results. The clinical trial programme with metrifonate has recently been suspended following a review of adverse events in the clinical data.

\section{Adverse events (AEs)}

Many of the side effects of the AChe inhibitors are attributable to peripheral cholinergic effects. Nausea, vomiting and diarrhoea were the most frequently reported.

Of the 2446 patients who received tacrine in clinical trials, 49\% had ALT levels greater than the upper limit of normal (ULN) on at least one occasion and $25 \%$ had ALT levels greater than three times the ULN. Although in all cases discontinuing tacrine reversed the elevation, the data suggested that careful monitoring of ALT levels was necessary for all patients on tacrine [49]. Other frequent drug-related AEs were nausea and/or vomiting, diarrhoea, abdominal pain, dyspepsia, and skin rash. Treatment-related AEs occurred in 34\% of patients receiving placebo and $51 \%$ of those on tacrine. The majority of adverse events (95\%) were mild to moderate in severity, as rated by the study physician [38]. No significant drug related effects on blood pressure, heart rate, or physical or neurological examinations were noted.

Cholinergic effects, such as gastrointestinal upset, were the predominant $\mathrm{AE}$ seen in all trials of donepezil and were predominantly described as mild to moderate and transient. Trials using low doses of donepezil, $1 \mathrm{mg}, 3 \mathrm{mg}$ and $5 \mathrm{mg}$ and placebo for a period of 12 weeks showed an incidence of AEs of $64 \%, 68 \%, 67 \%$ and $65 \%$ respectively [42]. In trials using higher doses, the number of AEs rose concomitantly. Fatigue, diarrhoea, nausea, vomiting and muscle cramps were more common $(P<0.05)$ in those patients on $10 \mathrm{mg}$ compared with both placebo and $5 \mathrm{mg}$ of donepezil during a 24 week trial [43]. This higher rate of AE at $10 \mathrm{mg}$ was attributed to rapid dose titration, since in open label phase the
$10 \mathrm{mg}$ dose was titrated more slowly and no excess AEs were seen. The overall incidence of AEs was 24\%, 40\% and $81 \%$ of patients randomized to placebo, $5 \mathrm{mg}$ and $10 \mathrm{mg}$ of donepezil respectively. In this trial, none of the serious adverse events reported (6\%) were felt to be treatment related [43]. The only laboratory abnormality reported was a low haemoglobin level in four patients receiving $10 \mathrm{mg}$ donepezil $(n=157)$, two of which were attributed to pre-existing disease. An interim report of open label donepezil treatment, showed the incidence of AEs after 92 weeks to be similar to the rates outlined above, and were also found to be transient in nature [45]. Of the 133 patients enrolled, there were 3 deaths, (felt to be unrelated to treatment) and 14 withdrawals, of which $79 \%$ were considered unrelated to treatment. No other abnormalities were seen in the laboratory analyses of both the placebo-controlled trials and the open label trial discussed above.

Treatment with rivastigmine was not associated with any increased risk for mortality, significant AEs, effects on laboratory parameters and ECGs, or cardiovascular vital signs. One death occurred in the study population during the trial but it was not considered related to drug treatment. Most AEs were mild to moderate, dose related and of limited duration. In the high dose group (6-12 $\mathrm{mg}$ ) the incidence of nausea and vomiting was $48 \%$ and $27 \%$ respectively compared with $11 \%$ and $3 \%$ in the placebo group. The nausea and vomiting occurred most commonly in the dose titration phase and resolved without treatment. The commonest other AEs were the cholinergic ones plus fatigue, (10\%) asthenia, (10\%) dizziness (24\%) and somnolence (9\%). Another interesting finding was that the mean body weight in the high-dose group decreased significantly $(1.78 \mathrm{~kg})$ while the placebo group increased by $0.50 \mathrm{~kg}$. There were no differences in transaminase levels between the rivastigmine treated group and the placebo group [46].

In metrifonate studies, nausea, vomiting and diarrhoea constituted $55 \%$ of all AEs and were generally mild and transitory. Diarrhoea, leg cramps and rhinitis were the only symptoms seen with higher dose metrifonate compared with placebo with a difference greater than $5 \%$ [22]. No adverse events were recorded in laboratory serum analysis, but a dose related reduction in heart rate was seen on ECG, with three patients withdrawing due to asymptomatic bradycardia during the loading phase [48]. No significant changes in blood pressure or weight were noted in either study.

\section{Clinical development}

With the continuing development of new AChe inhibitors, certain characteristics have been improved to meet clinical needs. Donepezil, rivastigmine and metrifonate 
have certain pharmacological differences from the earlier drug tacrine. Improved central selectivity for ACh enzyme inhibition is an important factor in the better side effect profile of donepezil and rivastigmine. A lack of CNS specificity in metrifonate treatment may play a part in the problems of muscular weakness under investigation. Tacrine's greater peripheral cholinesterase inhibition is reflected in a higher incidence of reported adverse effects, mostly gastrointestinal upset [37].

Donepezil, rivastigmine and metrifonate were developed with a longer duration of action. Tacrine has the shortest half-life, requiring dosage 4 times daily. Donepezil has the longest half-life $\left(t_{1 / 2} 70 \mathrm{~h}\right)$, and both donepezil and metrifonate can be given as a once daily preparation. Rivastigmine requires administration twice daily although this has been promoted as giving greater flexibility in dose adjustment. Generally it is accepted that less frequent regimens suit patients and carers alike. It is also postulated that better tolerability of the newer drugs is in part due to the smoother AChe inhibition achieved with longer duration of action. This avoids the fluctuations in enzyme inhibition, and lessening cholinergic side effects. The hepatotoxicity experienced in clinical trials with tacrine [49] has not been seen with the newer preparations, which are predominately excreted through the kidneys.

\section{Pharmacoeconomics}

A full review of the pharmacoeconomics of these drugs is beyond the scope of this article. Cost effectiveness is a contentious issue, particularly for treatment in diseases not previously addressed. In the case of AD and AChe inhibitors, demands have been much more extensive than for other disease treatments. The debate has been about cost, not cost effectiveness, and as a result there has been little focus on patients who may benefit from these agents. Cost effectiveness is much easier to demonstrate where there are hard end-points such as in cardiac failure or myocardial infarction rather than in areas of mental health such as schizophrenia, depression or AD. Recent estimates put the full cost of $\mathrm{AD}$ in the USA at $\$ 67.3$ billion, $31 \%$ of which is direct care cost, $49 \%$ unpaid caregiver cost and $20 \%$ the value of lost productivity due to illness and premature mortality [50]. UK estimates for 1996 indicate a total annual cost of $£, 5.36-£, 5.837$ million, of which $42 \%$ ( $£ 2.26-£ 2.45$ million) will fall to Health \& Social Services with the remaining 58\% being borne by the client or Department of Social Security [51]. Since AD affects cognition, ADL and behaviour, treatment with AChe inhibitors not only has direct benefits for the patient, but can reduce caregiver burden and delay institutionalisation. In the USA, earlier data suggested that tacrine produced savings of approxi- mately $\$ 4052$ per person [52]. In a small study, prevention of a 2-point decline in MMSE in moderate to severely demented elderly people living at home was seen to save US $\$ 3700$ each year [53]. It has been suggested that donepezil treated patients have a delay in deterioration in ADL for 1 year compared with placebo [54].

Recently attempts at analysing cost effectiveness have taken into consideration cost of care at each stage of disease and the rate of disease progression in treated and non-treated patients. When all these factors are evaluated, donepezil at $5 \mathrm{mg}$ and $10 \mathrm{mg}$ has been shown to be cost neutral [55]. This is explained by treated patients spending less time in the state of severe dementia, with the associated higher care cost. Cautious interpretation of this data is advised since it is based on a number of different clinical studies and also insufficient long term data led the authors to assume no differences in mortality rates for the donepezil and placebo group. Along with economic projections of cost in the future, the mortality rate is a key factor in projecting overall cost of care, and we await more accurate data on the survival rates of treated patients. A recent review also suggested that costs of symptomatic drug therapy could be completely offset if only a few months of institutional care could be avoided [51]. These projections would also largely be dependent on mortality rates.

\section{Role of AChe inhibitors in Alzheimer's disease}

Treatment with AChe inhibitors is simply one aspect of the package of care required for $\mathrm{AD}$ patients. Most specialists have a holistic approach, where pharmacological treatments are coupled with multidisciplinary team assessments of needs and institution of community supports where required. On full assessment and diagnosis of $\mathrm{AD}$, initiation of an AChe inhibitor is recommended as early as possible, since not all patients respond to treatment (30-40\%). It is important that family and carers fully understand the limitations of treatment. The Standing Medical Advisory Committee (SMAC) guidelines recommend withdrawal of the drug in the absence of any clinical response [56]. When a patient is seen to respond initially, the decision to withdraw treatment remains that of the clinician, and sometimes is at odds with the family's wishes. Full discussion when treatment is initiated can help to avoid any later misunderstanding. The effect of treatment extends beyond the pharmacological, involving psychological, social and financial aspects for both patient and carers. Despite the issues of cost, and in the absence of any other immediate developments, it is important that AChe inhibitor therapy is considered for patients with mild to moderate AD. 


\section{References}

1 Khann G, Drachman D, Folstein M, Katzman R, Price D, Stadlan EM. Clinical diagnosis of Alzheimer's disease: report of the NINCDS-ADRDA Work Group under the auspices of Department of Health and Human Services Task Force on Alzheimer's Disease. Neurology 1984; 34: 939-944.

2 Katzman R, Saitoh T. Advances in Alzheimer's Disease. FASEB J 1991; 5: 278-286.

3 Becker RE. Becker RE, Giacobini E, editors. Cholinergic Basis of Alzheimer Therapy. Boston: Berkhauser 1991. Therapy of the cognitive deficit in Alzheimer's disease; the cholinergic system. p. 1-22.

4 Cutler NR, Sramek JJ, Veroff AE. Alzheimer's Disease. Chichester: John Wiley and Sons, 1994.

5 Becker RE, Giacobini E. Mechanisms of cholinesterase inhibition in senile dementia of the Alzheimer type; clinical pharmacological and therapeutic aspects. Drug Dev Res 1988; 12: 163-195.

6 Avery EE, Baker LD, Asthana S. Potential role of muscarinic agonists in Alzheimer's Disease. Drugs Aging 1997; 11: 450-459.

7 Jorm AF. Effects of cholinergic enhancement therapies on memory function in Alzheimer's disease: a meta-analysis of the literature. Aust N ZJ Psychiatry 1986; 20: 237-240.

8 Rosen WG, Mohs RC, Davis KL. A new rating scale for Alzheimer's Disease. Am J Psychiatry 1984; 141: 1356-1364.

9 Stern RG, Mohs RC, Davidson M, Schmeidler J, Silverman J, Kramer-Ginsberg E. A longitudinal study of Alzheimer's disease; measurement rate and predictors of cognitive deterioration. Am J Psychiatry 1994; 151: 390-396.

10 Kramer-Ginsberg E, Mohs RC, Aryan M, et al. Clinical predictors of course for Alzheimer patients in a longitudinal study: a preliminary report. Psychopharmacol Bull 1988; 24: 458-462.

11 Guy W. ECDEU Assessment Manual for Psychopharmacology. Rockville, National Institute of Mental Health 76-388. 1976, Clinical Global Impressions.

12 Berg L, Miller JP, Baty J, Rubin EH, Morris JC, Fiegel G. Mild senile dementia of the Alzheimer type. Evaluation of intervention. Ann Neurol 1992; 31: 242-249.

13 Folstein MF, Folstein SE, McHugh PR. 'Mini-mental state'. A practical method for grading the cognitive state of patients for the clinician. J Psychiatr Res 1975; 12: 189-198.

14 Lawton MP, Brodie EM. Assessment of older people: self maintaining and instrumental activities of daily living. Gerontologist 1969; 11: 545-554.

15 Schwartz GE. Development and evaluation of the Geriatric Evaluation by Relative's Rating Instrument (GERRI). Psychol Reports 1983; 53: 479-488.

16 DeJong R, Osterlund OW, Roy GW. Measurement of quality of life changes in patients with Alzheimer's Disease. Clin Ther 1989; 11: 545-554.

17 Reisberg B, Ferris SH, de Leon MJ, Crook T. The Global Deterioration Scale for assessment of primary degenerative dementia. Am J Psychiatry 1982; 139: 1136-1139.

18 Cummings JL, Mega M, Gray K, Rosenberg-Thompson S, Carusi DA, Gornbein J. The neuropsychiatric inventory; comprehensive assessment of psychopathology in dementia. Neurology 1994; 44: 2308-2314.
19 Reisberg B, Borenstein J, Salob SP, Ferris SH, Franssen, Georgotas A. Behavioral symptoms in Alzheimer's disease: phenomenology and treatment. J Clin Psychiatry 1987; 48 Suppl: 9-15.

20 Peripheral and Central Nervous System Drugs Advisory Committee J. Rockville MD: Dept of Health and Human Services, Public Health Service, Food and Drug Administration 1989, 227.

21 The European Agency for the Evaluation of Medical Products Committee for Propriety Medicinal Products (CPMP) S1. Notes for guidance on medical products in the treatment of AD. EMEA 1997.

22 Morris JC, Cyrus PA, Orazem J, et al. Metrifonate benefits cognitive, behavioural, and global function in patients with Alzheimer's disease. Neurology 1998; 50: 1222-1230.

23 Rosler M, Anand R, Cicin-Sain A, et al. Efficacy and safety of rivastigmine in patients with Alzheimer's disease: international randomised controlled trial. Br Med J 1999; 318: 633-640.

24 Selen A, Balogh L, Siedlik P. Pharmacokinetics of tacrine in healthy subjects. Pharm Res 1988; 5: S218.

25 McNally W, Roth M, Young R. Quantitative whole-body autoradiographic determination of tacrine tissue distribution in rats following intravenous or oral dose. Pharm Res 1989; 6: 924-930.

26 Neilsen JA, Mena EE, Williams IH. Correlation of brain levels of 9-amino-1,2,3,4-tetrahydroaminoacridine (THA) with neurochemical and behavioral changes. Eur J Pharmacol 1989; 173: 53-64

27 Sugimoto H, Iimura Y, Yamanishi Y, Yamatsu K. Synthesis and anti-acetylcholinesterase activity of 1-benzyl-4-[5, 6-dimethoxy-1-indanon-2-yl] methylpiperidine hydrochloride (E2020) and related compounds. Bioorg Med Chem Lett 1992; 2: 871-876.

28 Rogers SL, Yamanishi Y, Yamatsu K. Becker R, Giacobini E, eds. Cholinergic Basis for Alzheimer Therapy. 3rd ed. Boston: Birkhäuser 1991 E2020-The pharmacology of a piperidine cholinesterase inhibitor. p. 314-320.

29 Bryson HM, Benfield P. Donepezil. Drugs \& Aging 1997; 10: $234-249$.

30 Rogers SL, Tiseo PJ, Friedhoff LT. Pharmacokinetics of donepezil HCL (E2020) are unchanged in patients with impaired renal function. Clin Pharmacol Ther 1997; 61: 217-220.

31 Anand R, Gharabawi G, Enz A. Efficacy and safety results of the early phase studies with Exelon (ENA 713) in Alzheimer's disease: an overview. J Drug Dev Clin Pract 1996; 8: 109-116.

32 Anand R, Gharabawi G. Clinical development of Exelon (ENA-713): the ADENA program. J Drug Dev Clin Pract 1996; 8: 117-122.

33 Enz A, Amstutz R, Boddeke H. Brain selective inhibition of acetylcholinesterase: a novel approach to therpy for Alzheimer's disease. Prog Brain Res 1993; 98: 431-438.

34 Reiner RE, Kraulhacker B, Simeon V, Skinjaric-Spoiler M. Mechanisms of inhibition in vitro of mammalian acetylcholinesterase and cholinesterase in solutions of 0,0-dimethyl 2,2,2-trichloro-1-hydroxyethyl phosphate (trichorphon). Biochem Pharmacol 1975; 24: 717-722.

35 Nordgren I, Bengtsson E, Holmstedt B, Pettersson BM. Levels of metrifonate and dichlorvos in plasma and 
erythrocytes during treatment of schistosomiasis with Bilarcil. Acta Pharmacol Toxicol 1981; 49 Suppl 5: 79-86.

36 Eagger SA, Levy R, Sahakian BJ. Tacrine in Alzheimer's disease. Lancet 1991; 337: 989-992.

37 Knapp MJ, Knopman DS, Solomon PR, Pendlebury WW, Davis CS, Gracon SI. A 30-week randomized controlled trial of high-dose tacrine in patients with Alzheimer's disease. The Tacrine Study Group. JAMA 1994; 271: 985-991.

38 Farlow M, Gracon SI, Hershey LA, et al. for the The Tacrine Study Group. A controlled trial of tacrine in Alzheimer's disease. JAMA 1992; 268: 2523-2529.

39 Knopman D, Schneider L, Davis K, et al. for the Tacrine Study Group. Long-term tacrine (Cognex) treatment: effects on nursing home placement and mortality. Neurology 1996; 47: 166-177.

40 Knopman D, Schneider L, Davis K, Gracon S, Smith F. Long-term tacrine treatment effects. Neurology 1998; 50: 567-8.

41 Qizilbash N, Whithead A, Higgins J, Wilcock G, Schneider L, Farlow M. Cholinesterase inhibition for Alzheimer disease. A meta-analysis of the tacrine trials. JAMA 1998; 280: $1777-1782$.

42 Rogers SL, Friedhoff LT, The Donepezil Study Group. The efficacy and safety of donepezil in patients with Alzheimer's disease; results of a US multicentre randomised double blind placebo-controlled trial. Dementia 1996; 7: 293-303.

43 Rogers SL, Farlow MR, Doody RS, Mohs R, Friedhoff LT, Donepezil Study Group. A 24 week double blind placebo controlled trial of donepezil in patients with Alzheimer's disease. Neurology 1998; 50: 136-145.

44 Rogers SL, Doody RS, Mohs RC, Friedhoff LT. Donepezil improves cognition and global function in Alzheimer disease: a 15-week, double-blind, placebo-controlled study. Donepezil Study Group. Arch Intern Med 1998; 158: 1021-1031.

45 Rogers SL, Friedhoff LT. Long-term efficacy and safety of donepezil in the treatment of Alzheimer's disease: an interim analysis of the results of a US multicentre open label extension study. Eur Neuropsychopharmacol 1998; 8: 67-75.

46 Corey-Bloom J, Anand R, Veach J, The ENA 713 B352 Study Group. A randomized trial evaluating the efficacy and safety of ENA 713 (rivastigmine tartrate), a new acetylcholinesterase inhibitor, in patients with mild to moderately severe Alzheimer's disease. Int J Geriatr Psychopharmacol 1998; 1: 55-65.

47 Becker RE, Colliver J, Elble R, et al. Effects of metrifonate, a long acting cholinesterase inhibitor, in Alzheimer's disease; report of an open trial. Drug Dev Res 1990; 19: 425-434.

48 Cummings JL, Cyrus PA, Bieber F, Mas J, Orazem J, Gulanski B, The Metrifonate Study Group. Metrifonate treatment of the cognitive deficits of Alzheimer's disease. Neurology 1998; 50: 1214-1221.

49 Watkins PB, Zimmerman HJ, Knapp MJ, Gracon SI, Lewis KW. Hepatotoxic effects of tacrine administration in patients with Alzheimer's disease. JAMA 1994; 271: 992-998.

50 Ernst RL, Hay JW. The US economic and social costs of Alzheimer's disease revisited. Am J Public Health 1994; 84: 1261-1264.

51 Bosanquet N, May J, Johnson N. Alzheimer's Disease in the United Kingdom. Health Policy Review 1998 no. 12.

52 Lubeck DP, Mazonson PD, Bowe T. Potential effect of tacrine on expenditures for Alzheimer's Disease. Med Interface 1994; (October): 130-138.

53 Ernst RL, Hay JW, Fenn C, Tinklenberg J, Yesavage JA. Cognitive function and the costs of Alzheimer disease. An exploratory study. Arch Neurol 1997; 54: 687-693.

54 Friedhoff LT, Rogers SL. Donepezil lengthens time to loss of activities of daily living inpatients with mild to moderate Alzheimer's Disease - results of a preliminary evaluation. Neurology 1997; 48: 2-26.

55 Stewart A, Phillips R, Dempsey G. Pharmacotherapy for people with Alzheimer's disease: A Markov-cycle evaluation of five years' therapy using donepezil. Int J Geriat Psychiatry 1998; 13: 445-453.

56 Standing Medical Advisory Committee. The use of Donepezil for Alzheimer's Disease. Department of Health, May 1998. 